\title{
Error analysis of hydraulic radius evaluation in hydraulic calculation
}

\author{
Ye Yin ${ }^{1}$, Dangwei Wang ${ }^{2,}$, Hantao Wang ${ }^{1}$, Anjun Deng ${ }^{2}$, and Shenghang Feng ${ }^{2}$ \\ ${ }^{1}$ Hubei Key Laboratory of Intelligent Yangtze and Hydroelectric Science, China Yangtze Power Co., \\ Ltd, Yichang, Hubei Province, China \\ ${ }^{2}$ State Key Laboratory of Simulation and Regulation of River Basin Water Cycle, China Institute of \\ Water Resources and Hydropower Research, Beijing, China
}

\begin{abstract}
Hydraulic radius is an important parameter in hydraulic calculation. It is often deemed that hydraulic radius can be replaced by the cross-sectional average water depth when the width to depth ratio $(B / H)$ is greater than a certain value in traditional. Based on the various artificial cross-section and natural ones, value-taking errors of hydraulic radius are studied in this paper. The results show that it is feasible to adopt the average water depth as the hydraulic radius when $B / H$ of rectangular section is larger than 40 or $B / H$ of isosceles triangular section is larger than 12. But for natural river, $B / H$ is different when water level changes and there is no single-valued corresponding relationship between relative error and $B / H$. Therefore, we advise that hydraulic radius could not be replaced by other variables in hydraulic calculation of natural rivers.
\end{abstract}

\section{Introduction}

As a very important parameter of a cross section, hydraulic radius, which is often used in water dynamics calculations, is defined as the ratio of the cross-section area to the corresponding wetted perimeter. For example, it can be used to estimate discharge by the Manning formula ${ }^{[1]}$ and to calculate water level by the Saint-Venant equations and so on ${ }^{[2]}$. Since the cross-sectional shape of natural river is complicated, it is difficult to measure the wetted perimeter, which causes much trouble in hydraulic radius calculation. It is supposed that when the ratio of water surface width to depth of a certain cross section is greater than 25 , the hydraulic radius could be replaced approximately by average depth of the cross section ${ }^{[3]}$. This view point has a great influence till now. Tang ${ }^{[4]}$ suppose that it is reasonable to adopt the $R=H$ in shallow water without vegetation. When analysing the resistance in the Yellow River estuary Hou ${ }^{[5]}$ still replaced the hydraulic radius by depth. Even more, the restrictions of the width to depth ratio is often be neglected and error be inevitably brought in practical application. Recently, with the development of the compute, it is possible to use the hydraulic radius directly in calculation and some researchers start to pay attention to the error of replacing the hydraulic radius by depth, some primary analysis of to the error characteristic have been done ${ }^{[6-7]}$ and some academician take hydraulic radius directly without replacing in their calculation ${ }^{[8]}$. Recently, a new and improved

*Corresponding author: wangdw17@126.com 
definition of hydraulic radius for closed conduits flowing partially full is presented to determine the channel discharge and friction slope of uniform flow ${ }^{[9]}$. Some results indicate that the Manning equation can successfully be used to study the localised pressure variations by taking into account the varying hydraulic radius and cross-sectional area of the tunnel ${ }^{[10]}$. But sometimes it is difficult to get the accurate geometry of the crosssections, so it is necessary to research on value-taking errors of hydraulic radius, which may give directions to practical application.

\section{Hydraulic radius and its character}

Hydraulic radius $R$ and average depth $H$ of a certain cross section can be expressed as ${ }^{[6]}$ :

$$
\begin{gathered}
R=\frac{A}{\chi} \\
H=\frac{A}{B}
\end{gathered}
$$

There, $A$ is the cross-sectional area, $\mathrm{m}^{2} ; B$ is the width of water surface, $\mathrm{m} ; \chi$ is the wetted perimeter, $\mathrm{m}$. Generically, $B$ is smaller than $\chi$, so $H$ is bigger than $R$. The relative error between $H$ and $R$ is:

$$
\varepsilon=\frac{H-R}{R}=\frac{\chi}{B}-1
$$

Obviously, the relative error is concerned with the shape of cross section. The hydraulic radius value-taking error of cross sections that have different shapes will be analysed in the following.

\subsection{Regular cross section}

\subsubsection{Rectangular section}

As shown in Fig. 1 (a), it will result in $A=B H_{\max }$ and $A=B H$, while $B$ is water surface width, $\mathrm{m} ; H_{\max }$ is the biggest depth in section, $\mathrm{m}$; and $H$ is cross-sectional average water depth, m.

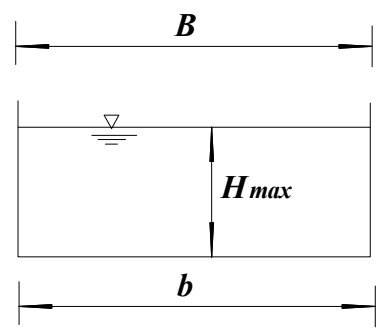

(a)Rectangular section

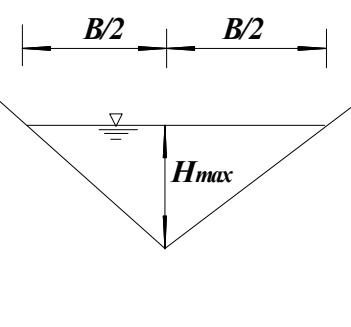

(b) Isosceles triangular section

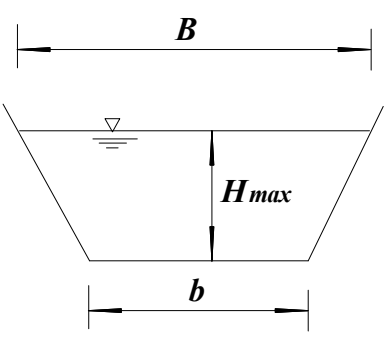

(c) Isosceles trapezoidal section

Fig. 1. Typical cross-section of the river channel.

The wetted perimeter of the rectangular section can be expressed as 


$$
\chi=B+2 H_{\max }=B+2 H
$$

Assuming that the width to depth ratio $\mu=B / H$, then

$$
\frac{\chi}{B}=\frac{B+2 H}{B}=1+\frac{2}{\mu}
$$

Introducing Eq. (4) into Eq. (3), the relative error between $H$ and $R$ will be expressed as following:

$$
\varepsilon=\frac{\chi}{B}-1=\frac{2}{\mu}
$$

The relationship between $B / H$ and $\varepsilon$ in rectangular section is shown in Table 1 .

Table 1. Relationship between $B / H$ and $\varepsilon$ in rectangular section.

\begin{tabular}{cccccccc}
\hline$B / H$ & 10 & 15 & 20 & 40 & 60 & 100 & 150 \\
\hline$\varepsilon(\%)$ & 20.00 & 13.33 & 10.00 & 5.00 & 3.33 & 2.00 & 1.33 \\
\hline
\end{tabular}

According to Table 1, the bigger the width to depth ratio $(B / H)$ in a rectangular section is, the smaller the relative error $(\varepsilon)$ is. If $\varepsilon$ couldn't surpass $5 \%, B / H$ should be bigger than 40 .

\subsubsection{Isosceles triangular section}

As it is shown in Fig. 1 (b), in isosceles triangular, its area is $A=B H_{\max } / 2$, what is more, $A=B H$, therefore $H_{\max }=2 H$. The wetted perimeter of an isosceles triangle cross section is given by

$$
\chi=2 \sqrt{\left(\frac{B}{2}\right)^{2}+\left(H_{\max }\right)^{2}}=2 \sqrt{4 H^{2}+\frac{B^{2}}{4}}
$$

then

$$
\frac{\chi}{B}=2 \sqrt{\frac{4}{\mu^{2}}+\frac{1}{4}}
$$

Introducing Eq. (7) into Eq. (3), the relative error between $H$ and $R$ will be got as following:

$$
\varepsilon=\frac{\chi}{B}-1=2 \sqrt{\frac{4}{\mu^{2}}+\frac{1}{4}}-1
$$

Table 2. Relationship between width to depth ratio and relative error of an isosceles triangular section.

\begin{tabular}{cccccccc}
\hline$B / H$ & 10 & 15 & 20 & 40 & 60 & 100 & 150 \\
\hline$\varepsilon(\%)$ & 7.70 & 3.49 & 1.98 & 0.50 & 0.22 & 0.08 & 0.04 \\
\hline
\end{tabular}

The relationship between $B / H$ and $\varepsilon$ in isosceles triangular section is shown in Table 2 . According to Table 2, the bigger $B / H$ in a triangular section is, the smaller $\varepsilon$ is. If $\varepsilon$ couldn't surpass $5 \%, B / H$ should be more than 12 . 


\subsubsection{Isosceles trapezoid section}

As it is shown in Fig. 1 (c), assuming that the width at the bottom of an isosceles trapezoidal cross section is $b$, its area can be expressed as

$$
A=(b+B) H_{\max } / 2
$$

Assuming that $\lambda=b / B$, Eq.(10) can be expressed as

$$
A=(1+\lambda) B H_{\max } / 2
$$

Then the wetted perimeter of this section may be written as

$$
\chi=2 \sqrt{H_{\max }^{2}+(B-b)^{2} / 4}+b=2 \sqrt{\left(\frac{2}{1+\lambda}\right)^{2} H^{2}+\left(\frac{1-\lambda}{2}\right)^{2} B^{2}}+\lambda B
$$

and

$$
\frac{\chi}{B}=2 \sqrt{\frac{4}{(1+\lambda)^{2} \mu^{2}}+\frac{(1-\lambda)^{2}}{4}}+\lambda
$$

Introducing Eq. (10) into Eq. (3), the relative error between $H$ and $R$ will be got as following:

$$
\varepsilon=\frac{\chi}{B}-1=2 \sqrt{\frac{4}{(1+\lambda)^{2} \mu^{2}}+\frac{(1-\lambda)^{2}}{4}}+\lambda-1
$$

It is obvious that the relative error $\varepsilon$ is concerned with not only $B / H$ but also $b / B$ in Eq. (11). In fact, a rectangular section and an isosceles triangular section can be considered as two special ones of isosceles trapezoidal cross sections. When the width at the bottom $b$ equals to $B$, namely $\lambda=1$, an isosceles trapezoid section is a rectangular section. When the width at the bottom $b$ equals to 0 , namely $\lambda=0$, an isosceles trapezoidal section is an isosceles triangular section.

The relationship among $B / H, \lambda$ and $\varepsilon$ is shown in Table 3 . If $\lambda$ is invariable, $\varepsilon$ will reduce as $B / H$ increases. If $B / H$ is invariable, as $\lambda$ increases, $\varepsilon$ will decrease at first and increase afterward and $\varepsilon$ will touch bottom when $\lambda$ is approximately 0.3 .

Table 3. Relationship among $B / H, \lambda$ and $\varepsilon$.

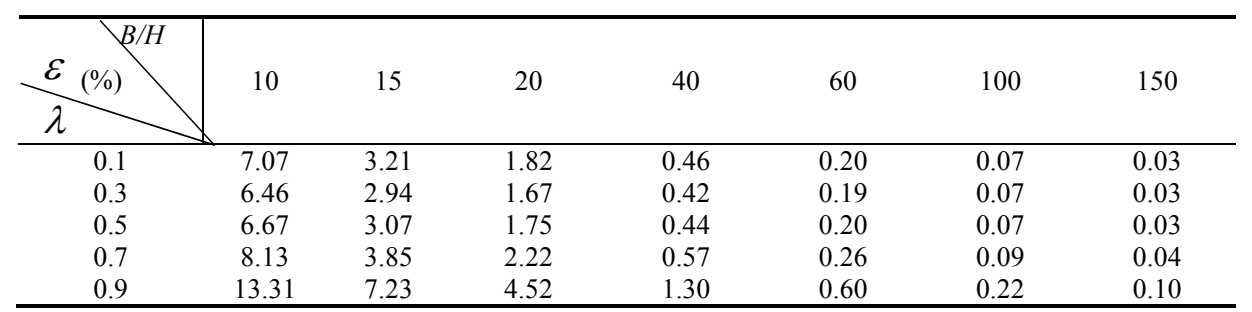

\subsection{Natural river section}

Above sections are regular, so we can use the mathematical expression to describe the relative error $\varepsilon$. But for complicated and diversified natural river section, it is difficult to infer $\varepsilon$. In natural river, when we want to calculate hydraulic radius and cross-sectional 
average water depth, a certain cross section is usually be divided into many sub-cross sections and area, width, wetted perimeter of each sub-cross section be calculated separately. So, area, width, and wetted perimeter of the whole cross section can be obtained by addition. And we can use Eq. (1) and Eq. (2) to calculate hydraulic radius and crosssectional average water depth of the cross section.

Fig. 2 shows the configuration of a natural cross-section. Fig. 3 shows the relations between different water level and $B / H$ in it. $B / H$ varies greatly at different water level. Such as, $B / H$ changes between 18 and 106 when the water level varies in the range of $26 \mathrm{~m}$ to 27 $\mathrm{m}$. The relationship between $B / H$ and $\varepsilon$ is shown in Fig. 4 and Fig. 5 shows the relationships among $\varepsilon, B / H$ and water level. $\varepsilon$ has a tendency to reduce along with the $B / H$ enlarging. But they don't have a single-valued relationship. The corresponding error is not always small when $B / H$ is big, vice versa. $\varepsilon$ may differ widely from each other when $B / H$ is nearly the same. For example, when the water level is $36 \mathrm{~m}$, the corresponding $B / H$ is $60, \varepsilon$ might still be $6 \%$. When water level is $26 \mathrm{~m}$ and $35 \mathrm{~m}$ respectively, the corresponding $B / H$ is about 40 , but $\varepsilon$ actually has great difference, $0.6 \%$ and $7 \%$ respectively.

Therefore, identical natural cross section couldn't be described generally by a fixed $B / H$. We should compute $B / H$ under each grade of water level and $B / H$ doesn't have sole corresponding relationships with $\varepsilon$. The view isn't advisable that it is possible to control the error into a certain scope when $B / H$ is bigger than a certain value.

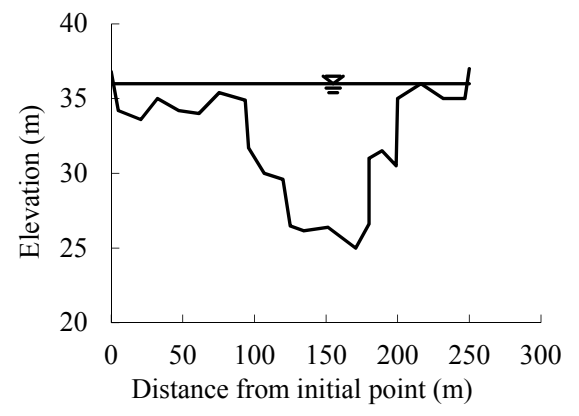

Fig. 2. Sketch map of a natural section.

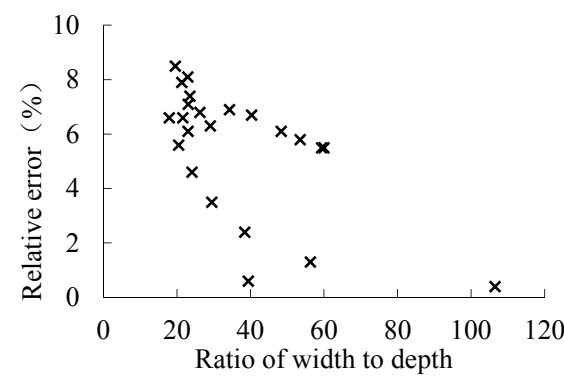

Fig. 4. Relation between $B / H$ and $\varepsilon$

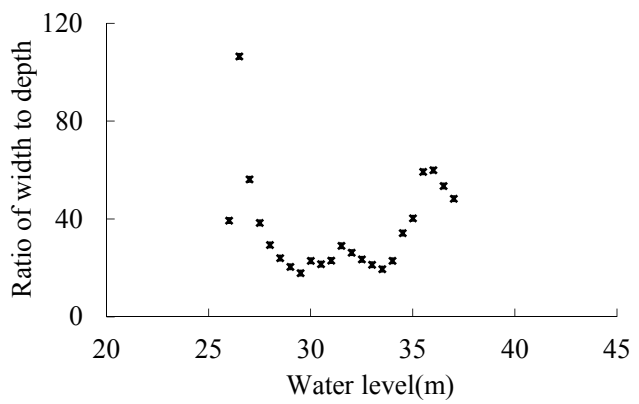

Fig. 3. Relation between water level and $B / H$.

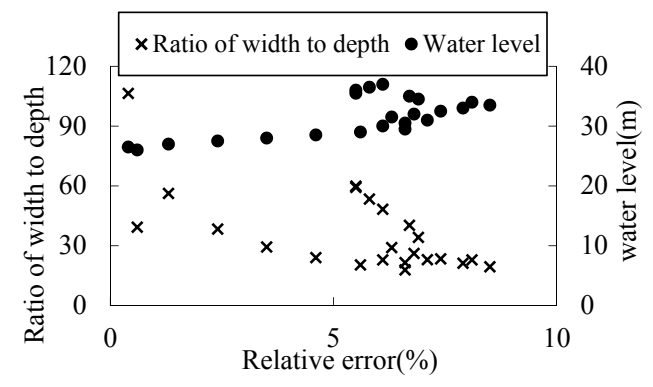

Fig. 5. Relation among $\varepsilon, B / H$ and water level

\section{Case studies}

Nansha Hydro-junction on Honghe River and Baihe Hydro-junction on Hanjiang River are taken as examples. The errors will be analysed which come from substitution crosssectional average water depth for hydraulic radius in the water-level computation. 
The continuity equation and the motion equation of 1D Saint-Venant equations may be given by

$$
\begin{gathered}
\frac{\partial Q}{\partial x}=q_{1} \\
\frac{\partial}{\partial x}\left(\frac{Q^{2}}{A}\right)+g A \frac{\partial Z}{\partial x}+g \frac{Q^{2} n^{2}}{A^{2} R^{4 / 3}}=0
\end{gathered}
$$

Where $Q$ is discharge, $\mathrm{m}^{3} / \mathrm{s} ; Z$ is water level, $\mathrm{m} ; n$ is the roughness coefficient; and $q_{1}$ is the lateral inflow discharge per unit of the width, $\mathrm{m}^{2} / \mathrm{s} ; x$ is the distance along river,m.

The discretization of Eq. (13) and (14) can be obtained by using the forward difference:

$$
\begin{gathered}
Q_{j+1}=Q_{j}+q_{1} \Delta x \\
Z_{j}=Z_{j+1}+\frac{1}{2 g}\left(\frac{Q_{j+1}^{2}}{A_{j+1}^{2}}-\frac{Q_{j}^{2}}{A_{j}^{2}}\right)+\frac{n^{2} \bar{Q}^{2}}{\bar{A}^{2} \bar{R}^{4 / 3}} \Delta x
\end{gathered}
$$

In Eq. (16) $\Delta x$ is the distance between two cross-sections, m; $\bar{Q}=\left(Q_{j}+Q_{j+1}\right) / 2$, $\bar{A}=\left(A_{j}+A_{j+1}\right) / 2, \bar{R}=\left(R_{j}+R_{j+1}\right) / 2$. Suffixes $j$ and $j+1$ are the tabs of upriver and downriver cross sections. The values of $Q_{j}$ and $Z_{j}$ of each cross section can be obtained by Equations (14) and (15).

Replacing hydraulic radius with cross-sectional average water depth, then Eq.(16) will be changed as

$$
Z_{j}=Z_{j+1}+\frac{1}{2 g}\left(\frac{Q_{j+1}^{2}}{A_{j+1}^{2}}-\frac{Q_{j}^{2}}{A_{j}^{2}}\right)+\frac{n^{2} \bar{Q}^{2}}{\bar{A}^{2} \bar{H}^{4 / 3}} \Delta x
$$

In the following the differences of water level will be inquired into further by two computation examples.

\subsection{Water level difference in Honghe River}

The Nansha hydroelectric power station is located at the middle reaches of Honghe River, in Yuanxian county, Yunnan province. It is a canyon-reservoir and the river valley is narrow. Its width is mainly in the range of $80 \mathrm{~m}$ to $100 \mathrm{~m}$. There are many rapids along the river, but there is no concentrated fall. The mean gradient of the river course is $1.17 \%$.In the natural situation, the roughness coefficient is between 0.03 and 0.05 .

$B / H$ and mean errors of calculating water-level by Eq.(16) under three different discharge of $Q=1000 \mathrm{~m}^{3} / \mathrm{s}, Q=2870 \mathrm{~m}^{3} / \mathrm{s}, Q=5470 \mathrm{~m}^{3} / \mathrm{s}$ are shown in Table 4 and Fig. 6 .

As it is shown, $B / H$ differs from each other greatly, and the bigger the discharge is, the smaller $B / H$ is. According to Fig.6, the water level calculated by Eq.(15) is lower than the one by Eq.(16). In addition, the larger the discharge is, the bigger the error is. When the discharge is $2870 \mathrm{~m}^{3} / \mathrm{s}, B / H$ varies from $24 \sim 36$ and the water-level error is in the range of $0.06 \mathrm{~m}$ to $0.25 \mathrm{~m}$. This can't be ignored in the water-level computation. In one word, it needs treating cautiously that taking place of hydraulic radius with cross-sectional average water depth. 
Table 4. The error of water-level computed.

by Eq. (16)

\begin{tabular}{|c|c|c|c|}
\hline $\begin{array}{l}\text { Discharge } \\
/ \mathrm{m}^{3} \cdot \mathrm{s}^{-1}\end{array}$ & 1000 & 2870 & 5470 \\
\hline$B / H$ & $28 \sim 45$ & $24 \sim 36$ & $16 \sim 22$ \\
\hline $\begin{array}{l}\text { The mean error } \\
\text { of water-level } \\
\qquad / \mathrm{m}\end{array}$ & -0.04 & -0.11 & -0.23 \\
\hline
\end{tabular}

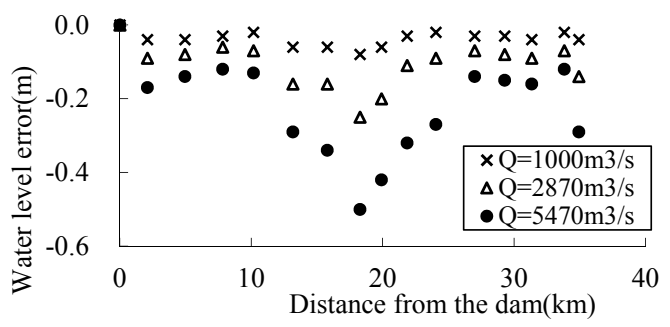

Fig. 6. Water-level calculating errors.

\subsection{Water level differencein Hanjiang River}

The Baihe hydroelectric power station is located at the trunk reach of Hanjiang River, between Baihe County of Shanxi Province and Yunxi County of Hubei Province. Baihe Reservoir is a channel-type reservoir, whose width is in the range of $250 \mathrm{~m}$ to $400 \mathrm{~m}$. The mean gradient of river is $0.6 \%$ and the roughness coefficient is between 0.03 and 0.038 .

The normal water level of Baihe Reservoir is $194.23 \mathrm{~m}$. The backwater caused by reservoir will affect 7 towns along Hanjiang River upstream of station. In order to confirm the scale of immigrants, ground expropriation and the protecting projects, the backwater must be calculated. And the losses of submergence will be obtained by the backwater level curve $\mathrm{e}^{[6]}$. The calculating results of flood water level are shown in Table 5.

Table 5. Contrast of results by Eq. (16) and Eq. (17).

\begin{tabular}{|c|c|c|c|c|c|c|c|}
\hline \multirow{2}{*}{ Typical cross section } & \multirow{2}{*}{$\begin{array}{l}\text { Distance from } \\
\text { The dam } / \mathrm{km}\end{array}$} & \multicolumn{2}{|c|}{$16900 \mathrm{~m}^{3} / \mathrm{s}$} & \multicolumn{2}{|c|}{$22900 \mathrm{~m}^{3} / \mathrm{s}$} & \multicolumn{2}{|c|}{$26400 \mathrm{~m}^{3} / \mathrm{s}$} \\
\hline & & Eq.(16) & Eq.(17) & Eq.(16) & Eq.(17) & Eq.(16) & Eq.(17) \\
\hline Shuhekou (T1) & 39.77 & 207.82 & 207.55 & 211.54 & 211.25 & 213.91 & 213.56 \\
\hline Xianhekou (T13) & 33.72 & 206.02 & 205.79 & 209.79 & 209.52 & 212.14 & 211.83 \\
\hline Latna railway station (T24) & 28.03 & 203.64 & 203.43 & 207.19 & 206.93 & 209.46 & 209.17 \\
\hline Yueritan (T59) & 9.11 & 197.47 & 197.39 & 200.05 & 199.94 & 202.17 & 202.06 \\
\hline Shibaogoukou (T70) & 3.54 & 195.54 & 195.5 & 197.53 & 197.49 & 199.57 & 199.52 \\
\hline Location of Baihe dam (T78) & 0.00 & 194.23 & 194.23 & 195.78 & 195.78 & 197.88 & 197.88 \\
\hline \multirow{2}{*}{\multicolumn{2}{|c|}{ Water-level mean error in whole reservoir/ $\mathrm{m}$}} & \multicolumn{2}{|c|}{-0.14} & \multicolumn{2}{|c|}{-0.17} & \multicolumn{2}{|c|}{-0.19} \\
\hline Mean $B / H$ in whole reservoir & & \multicolumn{2}{|c|}{$17 \sim 28$} & \multicolumn{2}{|c|}{$14 \sim 25$} & \multicolumn{2}{|c|}{$13 \sim 23$} \\
\hline
\end{tabular}

According to Table 5, the water level obtained by Eq. (17) is lower than the one by Eq.(16) under the same discharge. Apart from this, the larger the discharge is, the bigger the difference is. For example, the differences at Shuhekou (T1) are $0.27 \mathrm{~m}, 0.29 \mathrm{~m}$ and $0.35 \mathrm{~m}$ under three different discharges of $Q=16900 \mathrm{~m}^{3} / \mathrm{s}, Q=22900 \mathrm{~m}^{3} / \mathrm{s}, Q=26400 \mathrm{~m}^{3} / \mathrm{s}$. The mean water level errors of the whole reservoir section are:-0.14 $\mathrm{m},-0.17 \mathrm{~m}$ and $-0.19 \mathrm{~m}$ 。

It can be seen from above that using Eq.(16) in water-level computation can cause great error. Say it in another way, substitution cross-sectional average water $\operatorname{depth}(B / H)$ for hydraulic $\operatorname{radius}(R)$ will cause water level lower than reality, the site of the pinch-out point will nearer to the dam. As a result, it will make submerging area and losses smaller, which is not able to give right directions to immigrants and protecting projects.

\section{Conclusions}

Based on different cross sections, value-taking errors of hydraulic radius are studied in this paper. And the errors in water level calculating have been analysed by two practical examples. As a result, some conclusions and suggestions are obtained as follows: 
(1) As for a regular cross section, if the error isn't big than $5 \%$, it will be feasible to adopt $B / H$ as hydraulic radius when $B / H$ is bigger than 40 in rectangular section, or $B / H$ is bigger than 12 in an isosceles triangular one. In addition, the error is related with not only $B / H$ but also $b / B$ in an isosceles trapezoid section.

(2) In natural river, cross section should not be described generally by a fixed $B / H$, and $B / H$ may differ from each other greatly under different water levels for the same cross section. So there is no certain relationship between $B / H$ and relative error. The view is deserved to be suspected that it is possible to control the error into a certain range when $B / H$ is bigger than a certain value.

(3) In practice, not only in natural river but also in reservoir, the error caused by replacing hydraulic radius with cross-sectional average water depth can't be ignored. It will get a set of lower water surface than reality. The larger the discharge is, the bigger the error is. As a result, this make the estimation of the flooded area and the losses is less than it is in reality, which is not able to give right directions to work about immigrants in reservoir.

(4) As a result, it needs treating cautiously to take place of hydraulic radius with $B / H$. In order to improve the accuracy of computations, it is advised to use hydraulic radius directly when it is necessary.

\section{Acknowledgments}

This research work was supported by National Key Research and Development Program of China(2018YFC0407404), National Natural Science Foundation of China (U2040217), IWHR, SKL-WAC (Grant No. SE0145B372019) and State Key Laboratory of Watershed Water Cycle Simulation and Regulation (SKL2020ZY08).

\section{References}

1. Abdelhaleem F S, Amin A M A, Helal E E D Y . Mean flow velocity in the Nile River, Egypt: an overview of empirical equations and modification for low-flow regimes, Hydrological Sciences Journal (2020)

2. Zhang J M, Wang Y V, New iteration method for calculating water level of gradually varied steady flow ,J. Hydraul. Eng, 4, 4(2005) (in Chinese)

3. Xu Z F, Hydraulics(Higher education Press, Beijing, 1987)(in Chinese)

4. Tang H W, YanJ, XiaoY, Lu S Q, Manning's roughness coefficient of vegetated channels , J. Hydraul, Eng, 38, 7(2008) (in Chinese)

5. Hou Z J, Wang K R, Xiao X Y, Calculation and Analysis of Resistance in the Yellow River Estuary, Yellow River,30, 7 (2008)(in Chinese)

6. Cao X H, Xi G P,Error Analysis of Hydraulic Computation of Open Channel by Use of Manning Equation, Journal of Heilongjiang Hydraulic Engineering College, 9, 2 (2007)

7. Lin Z X, Error Analysis of Flow Computation by Gradient Area Law, Water Resources and Power, 26, 4 (2008) (in Chinese)

8. XueH, Sun D. P, Zhao N, A coupling model and its application in estuary area, Journal of Hydrodynamics, 21, 7 (2006) (in Chinese)

9. VatankhahAli R, Ghafari S,MahdaviMazdeh A,New and improved hydraulic radius for channels of the second kind,Ain Shams Engineering Journal, 6, 7, (2015)

10. Andersson L R, Hellstrm J G I, Andreasson P, Numerical Investigation of a Hydropower Tunnel: Estimating Localised Head-Loss Using the Manning Equation, Water, 11, 8 (2019) 